\title{
Estudo sobre a contribuição da Ciência da Informação em pesquisas sobre Tecnologias Assistivas
}

\author{
Study on the contribution of Information Science in research on Assistive \\ Technologies
}

\section{Estudio sobre la contribución de la Ciencia de la Información en la investigación sobre las ayudas técnicas}

\author{
Osvaldo de Souzal \\ Hamilton Rodrigues Tabosa ${ }^{2}$
}

\begin{abstract}
Resumo
Apresenta, conceitua e discute o tema da mediação da informação relacionando-o ao conceito de tecnologias assistivas, contextualizando a discussão no âmbito das competências da Ciência da Informação $(\mathrm{CI})$. Apresenta a contribuição da CI para o alcance de soluções técnico-práticas relativas à problemática abordada, por meio de um levantamento bibliográfico sobre o tema "acessibilidade informacional" em periódicos científicos durante os anos de 2013 a 2016, tendo sido utilizada a técnica de Análise de Conteúdo para analisar e categorizar o corpus documental da pesquisa, com base em seus objetivos gerais. Como resultados, evidencia o baixo nível de contribuição da CI na proposta de soluções para problemas de mediação da informação com o uso de tecnologias e que as publicações são relativamente parcas e os resultados das pesquisas na área poderiam ser bem mais profícuos, se propusessem inovações tecnológicas que efetivamente impactassem no modo como os deficientes, por exemplo, se apropriam da informação e a usam.
\end{abstract}

Palavras-Chave: Mediação da informação. Tecnologias assistivas. Acessibilidade. Processamento de Linguagem Natural.

\begin{abstract}
This paper presents, conceptualizes and discusses the subject of information mediation, relating it to the concept of assistive technologies, contextualizing the discussion within the scope of Information Science (IC) competences. It presents a vision, in the chronological section from 2013 to 2016, of CI's contribution to the reach of technical-practical solutions related to the issue addressed, through a bibliographical survey on the theme "informational accessibility" in scientific journals during the years of 2013 to 2016, using the Content Analysis technique to analyze and categorize the documentary corpus of this research, based on its general objectives. As results, it shows the low level of contribution of IC in the proposal of solutions to problems of information mediation with the use of technologies and that the publications are relatively sparse and the results of the researches in the area could be much more proficient, if they proposed technological innovations which effectively impact the way the disabled, for example, appropriate and use information.
\end{abstract}

\footnotetext{
${ }^{1}$ Professor adjunto da Universidade Federal do Ceará, vinculado ao Departamento de CI e ao Programa de Pósgraduação em CI. É doutor em Engenharia de Teleinformática pela UFC. Coordena o Grupo de Pesquisa de Aplicações em Tecnologias Assistivas e Usabilidade. E-mail: osvsouza@ gmail.com.

${ }^{2}$ Doutor em Ciência da Informação pela UFPB. Mestre em Avaliação de Políticas Públicas e Graduado em Biblioteconomia pala UFCE. Professor do Departamento de Ciências da Informação da UFC. E-mail: hrtabosa@gmail.com.
}

Comun. \& Inf., Goiânia, GO, v. 21, n. 1, p. 70-88, jan./mai. 2018. 
Keywords: Information Mediation. Assistive Technologies. Accessibility. Natural Language Processing.

\section{Resumen}

Presenta, define y discute el tema de la mediación de la información relacionada con el concepto de tecnologías de asistencia, la contextualización de la discusión de la competencia de Ciencias de la Información (CI). Presenta una visión, en corte cronológico 2013-2016, la contribución de CI a la consecución de soluciones técnicas y prácticas para el problema planteado por medio de una revisión de la literatura sobre el tema "acceso a la información" en revistas científicas durante los años 2013 hasta el año 2016 y se utilizó la técnica de análisis de contenido para analizar y clasificar el corpus documental de la investigación, en función de sus objetivos generales. Como resultado, muestra el nivel de CI baja de la contribución de las soluciones propuestas para los problemas de información de mediación con el uso de la tecnología y que las publicaciones son relativamente escasos y los resultados de la investigación en el área podrían ser más fructífera, conspirado innovaciones tecnológicas lo que efectivamente impactassem en cómo las personas con discapacidad, por ejemplo, apropiarse de la información y usarla.

Palabras clave: Mediación de la información. Tecnologías de asistencia. Accesibilidad. Procesamiento del Lenguaje Natural.

\section{INTRODUÇÃO}

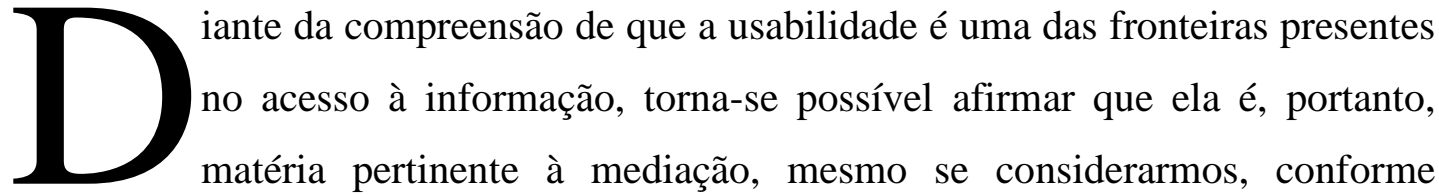
argumentam Nicholl e Boueri Filho (2001), a dificuldade de estabelecer um conceito unívoco e plenamente adequado para o termo, mesmo em um único idioma, dada a amplitude de sua prática e ambientes de aplicação e avaliação. Assim, costuma-se utilizar definições oficiais, como a da ISO (1998), que identifica os fatores que influenciam a usabilidade: "eficácia, eficiência e satisfação ${ }^{3}$ pelas quais usuários específicos podem atingir metas específicas em ambientes específicos [...]”.

Diante disso, torna-se necessário considerar os vários aspectos da mediação no fluxo informacional, não sendo possível desassociar tal compreensão das implicações relativas ao necessário envolvimento do profissional da informação nas questões pertinentes à usabilidade.

\footnotetext{
${ }^{3}$ A norma estabelece o entendimento desses termos como: "Eficácia" trata do grau de inteireza e exatidão pela qual usuários específicos podem atingir resultados específicos em ambientes especificados. "Eficiência" compara os recursos e esforços despendidos, com a exatidão e a inteireza das metas atingidas. "Satisfação" considera o conforto e grau de aceitação do sistema por seus usuários e por outras pessoas afetadas pelo seu uso.
}

Comun. \& Inf., Goiânia, GO, v. 21, n. 1, p. 70-88, jan./mai. 2018. 


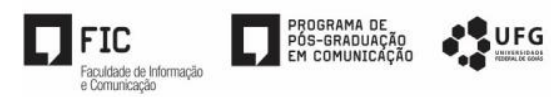

Estabelecendo-se esse entendimento como premissa fundamental neste texto, lançamos um olhar crítico sobre as implicações do uso das tecnologias assistivas (TA) sobre o tema.

Ao analisarmos o assunto, depreende-se que é necessária uma percepção pragmática sobre o termo tecnologias assistivas, tendo em vista que é possível encontrar muitas definições para ele. Cook e Hussey (1995), por exemplo, argumentam que por TA pode-se entender uma série de equipamentos, serviços, estratégias e práticas criadas e destinadas com vistas a atenuar os problemas funcionais encontrados pelos indivíduos com deficiências.

Crespo, Espada e Burgos (2016), por sua vez, rotulam-na pelas suas descrições e argumentações, como adaptações com vistas a aumentar a acessibilidade, que pode ser considerada, conforme Nicholl e Boueri Filho (2001, p. 49), "como a possibilidade e condição de alcançar os elementos funcionais do ambiente construído, para assim permitir sua utilização".

Para Bersch e Tonolli (2006), TA é um termo utilizado para identificar todo o conjunto de recursos e serviços que colaboram para facilitar ou ampliar habilidades funcionais de pessoas com deficiência e, consequentemente, favorecer a vida independente e a inclusão. Segundo Bersch (2008) e Melo, Costa e Soares (2006), TA - também chamadas de Adaptativas ou Ajuda Técnica - funcionam como ampliadoras de habilidades funcionais ou da realização de funções desejadas, mas que estejam interditadas devido à deficiência ou ao envelhecimento, de modo a aumentar a autonomia, a independência, a qualidade de vida e a inclusão social.

Em outras palavras, é qualquer instrumento que facilite a pessoa com deficiência ou habilidades reduzidas a realizar alguma atividade, não se restringindo, todavia, a esses grupos de pessoas. Tal instrumento pode consistir, por exemplo, de um simples apetrecho de madeira, como uma bengala (que auxilia no deslocamento geoespacial de uma pessoa com deficiência ou habilidade motora reduzida), até um sofisticado software que permita a um usuário cego ou com capacidade visual reduzida acessar a Web.

Assim, percebe-se que TA abrange uma gama de estratégias, produtos, serviços e equipamentos que são utilizados para fazer com que pessoas com deficiência tenham mais qualidade de vida, favorecendo-lhes o aumento de autonomia e inclusão, em suas várias acepções, sejam arquitetônicas, sociais, tecnológicas ou educacionais.

Em um sentido mais genérico, que talvez consista em um conceito ampliado para o termo TA, podem-se abranger outros produtos e serviços não exclusivamente destinados às pessoas com deficiência, mas voltados para a ampliação das capacidades funcionais de qualquer pessoa. Nessa categoria de produtos, pode-se citar, por exemplo, um binóculo (que amplia a

Comun. \& Inf., Goiânia, GO, v. 21, n. 1, p. 70-88, jan./mai. 2018. 
capacidade visual), uma escada rolante (facilita a mobilidade), um software sumarizador de textos (amplia a capacidade de acesso à informação), e todos os demais tipos de recursos, cuja finalidade seja a acessibilidade informacional.

Para elucidarmos nossa compreensão a respeito do termo acessibilidade informacional, tomamos por base o supracitado conceito de Nicholl e Boueri Filho (2001) e a descrevemos como a viabilidade de se alcançar os elementos funcionais do ambiente informacional, seja analógico ou digital, de modo a permitir sua utilização irrestrita por quaisquer tipos de públicos-alvo, com necessidades heterogêneas ou não.

Partindo dessa compreensão, e concordando com Borko (1968), ao afirmar que a Ciência da Informação (CI) investiga as propriedades e o comportamento da informação, para melhorar a acessibilidade e a usabilidade, parece razoável afirmar que problemas de acessibilidade informacional são pertinentes à CI, considerando que a ela cabem estudos sobre os fenômenos informacionais, seus problemas e possíveis soluções.

Nesse sentido, o presente estudo lança as seguintes questões: têm os estudos sobre acessibilidade informacional, dentro da CI, colaborado efetivamente para a superação de problemas? Que soluções técnico-práticas ou inovações a CI tem desenvolvido no âmbito da acessibilidade informacional?

Soluções técnico-práticas ou inovações, no escopo deste artigo, são aquelas que apresentam resultados que podem de fato contribuir para a melhoria da acessibilidade informacional, são ações que vão além da discussão e trazem contribuições que avançam o campo teórico, ou que acrescentam algum método ou ferramenta que pode ou tem potencial de ser realmente usado.

No sentido de se obter respostas para essas perguntas, organizamos o presente estudo de forma a alcançar o seguinte objetivo geral: conhecer as aplicações e as limitações dos estudos sobre acessibilidade informacional desenvolvido na CI.

\section{A CIÊNCIA DA INFORMAÇÃO E A ACESSIBILIDADE INFORMACIONAL}

A CI tem se envolvido, de maneira ampla, nas questões relativas à coleta, ao processamento, ao armazenamento, à recuperação e ao uso da informação. Justifica-se esse envolvimento por compreender que "O mais importante em CI (como na política de informação) é considerar a informação como uma forma constitutiva na sociedade" (CAPURRO; HJORLAND, 2003, p. 345, tradução nossa). 
$\mathrm{Na}$ busca pela compreensão de problemas relativos aos fenômenos informacionais, a CI lança mão de alianças interdisciplinares. Em Moraes e Carelli (2016, p. 154), aponta-se para o envolvimento de 45 diferentes áreas do conhecimento, das quais a CI importa conhecimento. Essa busca por apoio em outras áreas pode ser justificada, por exemplo, compreendendo-se que se deve dar respostas aos problemas identificados no fluxo informacional, mesmo que, para tanto, utilizem-se métodos, ferramentas ou teorias de outras áreas.

De fato, o esforço empreendido pela CI justifica-se ao se considerar que, em uma sociedade que tem como uma das características marcantes o alto nível de oferta de informação e, como outra característica, o desejo pela inclusão social e informacional, é inconcebível que alguma parcela da população deixe de ter acesso à informação por causa de algum tipo de restrição como, por exemplo, aquelas impostas pelo suporte da informação utilizado. Tais suportes, por vezes, impõem barreiras às pessoas com algum nível de deficiência (PAULA, 2009).

Embora a questão de usabilidade seja um fator crítico para que deficientes utilizem os programas de computador, notadamente os programas que têm por função recuperar informações, a usabilidade (a ausência ou presença dela) afeta a todos. Percebe-se que no uso de um programa de computador deve-se, idealmente, experimentar positivamente as qualidades ergonômicas propostas por Bastien e Scapin (1993).

Deve-se ter em mente que a acessibilidade e a usabilidade são pertinentes, embora não exclusivas, à CI. Na clássica compreensão de Borko (1968) sobre a CI, a acessibilidade e a usabilidade são consideradas como atividades-fim, ou seja, como o objetivo final, como a razão de ser da área, então vejamos:

Ciência da Informação é a disciplina que investiga as propriedades e o comportamento da informação, as forças que regem o fluxo de informação e os meios de processamento da informação para melhor acessibilidade e usabilidade. Ela está preocupada com o corpo de conhecimento relacionado com a origem, coleta, organização, armazenamento, recuperação, interpretação, transmissão, transformação e utilização da informação (BORKO, 1968, p. 3, tradução nossa).

Os termos "acessibilidade", "usabilidade" e "utilização da informação" remetem, portanto, a todo o processo que envolve a coleta de informação, o processamento e os fluxos de informação, todos culminando na recuperação e uso da informação, conforme Souza e Tabosa (2015).

Comun. \& Inf., Goiânia, GO, v. 21, n. 1, p. 70-88, jan./mai. 2018. 
Sobre as questões relativas à acessibilidade no uso da informação, Souza (2015) analisa o envolvimento da CI no estudo de questões relativas à usabilidade quando ela se relaciona a sistemas de informação e aponta que a CI participa em cerca de 5 (cinco) por cento das pesquisas sobre o tema.

Conclui-se pelo exposto que cabe, portanto, à CI (ainda que não exclusivamente) procurar resolver os problemas de acessibilidade e usabilidade relativos a questões que envolvam fenômenos informacionais ou, no mínimo, atenuá-los, uma vez que essa área tem reclamado para si a responsabilidade de investigar, compreender e atuar em todas as questões relacionadas à informação, notadamente, em seu consumo.

Deve-se compreender, de forma bem clara e evidente, que os problemas relacionados ao grande volume de informações é pauta urgente. De fato, já o é há bastante tempo. Veja-se que em Saracevic (1996, p. 60) (muito antes da forte presença da internet na facilitação do acesso à informação) discute-se "a tarefa massiva de tornar mais acessível um acervo crescente de conhecimento". O autor afirma ainda:

[...] assim como todos os problemas mais específicos que se seguiram estão ainda à nossa volta e estarão aí com ou sem a CI. A questão de se aplicar a tecnologia da informação na solução dos problemas informacionais continua e continuará com ou sem a CI. A evolução da ecologia informacional pode se processar com ou sem a CI. Existindo ou não um campo organizado chamado CI, os problemas não terminarão. Os problemas estão aí, independentemente de sua rotulação (SARACEVIC, 1996, p. 60).

Diante dessa afirmação, pressupõe-se que a CI deve atuar de maneira que, tomando teorias emprestadas ou usando as suas próprias, se houver, produza soluções para problemas informacionais. Essas soluções podem compreender, por exemplo, aspectos da mediação da informação, novas linguagens documentárias, produtos e ou serviços de informação, entre outros expedientes.

Evidencie-se que para as pessoas sem deficiência, a tecnologia torna as coisas mais fáceis; para as pessoas com deficiência, a tecnologia as torna possíveis (RADABAUGH, 2008). Por meio dessa máxima, o autor expressa bem o entendimento que se pretende dar ao uso da tecnologia no âmbito da CI. Se uma determinada ferramenta tecnológica pode, efetivamente, facilitar o acesso à informação, de maneira a influenciar positivamente a mediação da informação, como tal tecnologia pode deixar de ser usada?

É nesse sentido que se compreendem as TA como instrumentos para a mediação da informação, tal como conceituada por Almeida Júnior (2009, p. 92): 
Toda ação de interferência - realizada pelo profissional da informação -, direta ou indireta; consciente ou inconsciente; singular ou plural; individual ou coletiva; que propicia a apropriação de informação que satisfaça, plena ou parcialmente, uma necessidade informacional.

Assim, a mediação da informação é uma atividade que ocorre entre a informação e o sujeito que dela necessita, sendo executada, a exemplo, pelo profissional da informação, mesmo que inconscientemente, para a satisfação do sujeito demandante. Partindo-se desse entendimento, chega-se à fácil conclusão de que praticamente todas as atividades do profissional de informação estão vinculadas à mediação, uma vez que na própria natureza de sua atuação está o favorecimento de acesso à informação.

Para Almeida Júnior e Bortolin (2007), a mediação da informação pode ser dividida em explícita e implícita. A explícita se dá nas atividades fins dos equipamentos informacionais, principalmente no setor ligado diretamente ao atendimento do usuário. A mediação implícita ocorre nas atividades meio, como a aquisição, o processamento técnico, etc. Os autores afirmam que, em relação à área de CI, o seu objeto de estudo passaria a ser mais a mediação do que mesmo a informação.

Dessa forma, as TA surgem como instrumentos de mediação, para que sejam atendidas as demandas de usuários de informação com necessidades peculiares. Conforme Melo, Costa e Soares (2006) existem TA de diversos tipos e com diferentes propósitos como, por exemplo, para auxiliar na locomoção, no acesso à informação e na comunicação, no controle do ambiente e em diversas atividades do cotidiano como o estudo, o trabalho e o lazer. Cadeiras de rodas, bengalas, órteses e próteses, lupas, aparelhos auditivos e os controles remotos são apenas alguns exemplos. Os autores classificam as TA em dois grupos:

a) Tecnologias Assistivas para auxiliar em atividades do dia a dia, tais como:

- Equipamentos de auxílio à mobilidade, como cadeiras de rodas e bengalas;

- Lupas eletrônicas. Desenvolvidas para auxiliar pessoas com baixa visão, que necessitam de grande ampliação de textos e imagens, na leitura e na escrita;

- Assinadores. Peças plásticas ou de metal, vazadas em posições que auxiliam no preenchimento ou assinatura de documentos;

- Balanças com marcação em alto relevo - auxiliam pessoas com deficiência visual na medição de pesos;

- Máquina Perkins, que é utilizada na produção de textos em Braille;

- Reglete, que auxilia na escrita em grafia Braille;

Comun. \& Inf., Goiânia, GO, v. 21, n. 1, p. 70-88, jan./mai. 2018. 
- Trenas com marcação em alto relevo, que auxiliam pessoas com deficiência visual na medição de áreas.

b) Tecnologias Assistivas para auxiliar o uso do computador:

- Dispositivos apontadores alternativos. Alternativas ao mouse que viabilizam o acionamento de elementos de uma interface gráfica e a seleção de seu conteúdo;

- Teclados alternativos. Dispositivos físicos ou programas de computador que oferecem uma alternativa para o acionamento de teclas, simulando o funcionamento do teclado convencional;

- Ponteiras de cabeça. Ferramentas que podem ser acopladas à cabeça para auxiliar, por exemplo, o uso do teclado por pessoas que tenham dificuldades em usá-lo da forma convencional;

- Sistemas para entrada de voz (speech recognition). Viabilizam o uso do computador por comando de voz e assim podem ser utilizados por pessoas que estejam com a mobilidade dos membros superiores comprometida;

- Ampliadores de tela. São aplicativos que ampliam parte do conteúdo apresentado na tela do computador e assim podem facilitar seu uso por pessoas com baixa visão;

- Leitores de tela com síntese de voz. São aplicativos que viabilizam a leitura de informações textuais via sintetizador de voz e assim podem ser utilizados por pessoas com deficiência visual, por pessoas que estejam com a visão direcionada a outra atividade, ou até mesmo por aquelas que tenham dificuldade para ler;

- Linhas Braille. Dispositivos de saída compostos por fileira(s) de células Braille eletrônicas, que reproduzem informações codificadas em texto para o sistema Braille e assim podem ser utilizadas como alternativa aos leitores de tela por usuários que saibam interpretar informações codificadas nesse sistema;

- Impressoras Braille, entre outros.

Martins Neto e Rollenberg (2005) afirmam que a classificação internacional, Norma ISO 9.999, utiliza a denominação de Ajudas Técnicas e estabelece uma classificação em 10 classes assim definidas: Classe 03 - ajudas para terapia e treinamento; Classe 06 - próteses e órteses; Classe 09 - ajudas para cuidados pessoais e proteção; Classe 12 - ajudas para mobilidade; Classe 15 - ajudas para atividades domésticas; Classe 18 - mobiliário e adaptações para residências e outros locais; Classe 21 - ajudas para comunicação, informação e sinalização; Classe 24 - ajudas para o manuseio de bens e produtos; Classe 27 - ajudas e equipamentos para melhorar o ambiente, ferramentas e máquinas; e Classe 30 - ajudas para o lazer.

Comun. \& Inf., Goiânia, GO, v. 21, n. 1, p. 70-88, jan./mai. 2018. 
Relacionam-se, então, ao campo da CI, a segunda tipologia de TA proposta por Melo, Costa e Soares (2006) - destinadas a auxiliar no uso do computador - e a Classe 21 da ISO 9.999 - ajudas para comunicação, informação e sinalização - como tecnologias facilitadoras/viabilizadoras de acesso à informação, incluindo, embora com algumas limitações e especificidades, a tecnologia ligada à produção e leitura de textos em Braille, presentes no primeiro grupo de Melo, Costa e Soares.

Assim, percebe-se que a CI poderia contribuir com pesquisas e desenvolvimento de produtos capazes de ampliar o acesso à informação por parte de pessoas cegas ou com capacidade visual reduzida, seja identificando problemas e/ou falhas nas tecnologias já existentes ou identificando as necessidades dos usuários, de modo a propor melhorias ou mesmo a criação de novos instrumentos assistivos. Em nossa opinião, essa é uma área na qual a CI pode empreender soluções técnico-práticas ou inovações.

Almeja-se que a CI assuma para si o papel social e político de promover a inclusão informacional, notadamente do grupo daqueles com dificuldades para obter acesso à informação usando-se as ferramentas tradicionais, aos quais se incluem nesse grupo, por exemplo, os deficientes visuais e os surdos. Compreende-se que o uso de ferramentas não tradicionais, para além dos usuais sistemas de recuperação de informação, normalmente presentes em unidades de informação, aproxima a CI ao uso da tecnologia.

Essa aproximação em nada deve ser estranha à CI. Apropriando-se do conceito de tecnologia, apresentado por Vieira Pinto (2005), idealiza-se humanizar cada vez mais a mediação da informação tornando-a mais confortável e assistiva, justamente pelo uso da tecnologia. A tecnologia deve ser uma ferramenta produtiva para a CI. Todavia, de que ferramentas (próprias ou emprestadas) dispõem a CI para minimizar as dificuldades e facilitar a mediação da informação para esse grupo? Quais são as nossas propostas de soluções técnicopráticas ou inovações?

Estudos sobre esse tema já foram desenvolvidos dentro do escopo da CI, como exemplo tomamos Santos e Araújo (2015), Souza et al. (2013) e Caran, Santini e Biolchini (2016). No entanto, considera-se que uma parte desses estudos não se presta a desenvolver ou criar mecanismos ou instrumentos que promovam a ampliação das capacidades de acesso e uso da informação por parte de grupos específicos de usuários, mas se tratem de estudos nos quais apenas aborda-se a temática e evidencia-se a necessidade de haver mais iniciativas na melhoria da acessibilidade informacional. 


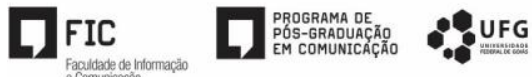

$\mathrm{Na}$ esteira desse raciocínio, vislumbra-se a potencialidade de aumento da acessibilidade informacional e, por conseguinte, da qualidade de vida e mesmo da produtividade das pessoas cegas ou com baixa visão, se elas tivessem à mão softwares capazes de realizar operações complexas com a informação em linguagem natural, inclusive no formato textual.

Uma das possibilidades vislumbradas consiste na produção automática de resumos de textos. As pesquisas no campo do Processamento de Linguagem Natural (PLN) orientam-se na busca por soluções para a manipulação da linguagem, com vistas a diversas aplicações, inclusive à produção automática de resumos de textos, bem como à tradução e à busca de informações em textos, como visto, por exemplo, em Pontes, Linhares e Torres-Moreno (2014).

Corroborando com isso, Pereira (2011, p. 2) afirma que o PLN "consiste no desenvolvimento de modelos computacionais para a realização de tarefas que dependem de informações expressas em uma língua natural”. No mesmo entendimento, Gonzalez e Lima (2003, p. 3) argumentam que o PLN "trata computacionalmente os diversos aspectos da comunicação humana, tais como sons, palavras, sentenças e discursos, considerando formatos e referências, estruturas e significados, contextos e usos".

Uma aplicação direta do PLN, como ferramenta para a assistividade na mediação informacional, consiste em resumir textos, com o mínimo possível de perda semântica e também sintetizar voz no idioma dos leitores, ampliando-lhes a capacidade de selecionar, entre uma quantidade enorme de opções, os textos que melhor suprem suas necessidades de informação. Dessa forma, os usuários da ferramenta poderiam ganhar tempo nessa etapa de seleção de material informacional, para dedicar-se, com mais afinco, à leitura e/ou (audição) do texto completo dos documentos previamente selecionados.

Para a criação de uma ferramenta que produza resumos automáticos de textos baseada em PLN, torna-se necessária a obtenção e/ou criação de bases de dados estatísticos sobre as palavras do idioma relativo aos textos. Tais estatísticas, no entanto, são raras e demandam enorme volume de dados (textos) e complexos procedimentos computacionais para serem produzidas. Uma forma alternativa ao uso de bases de dados estatísticos seria utilizar alguma outra estrutura de mapeamento das relações das palavras em frases, ou ainda, algum método que permitisse que fossem aplicados rótulos de classificação das frases ou dos trechos de frases.

Para o uso de uma técnica de aplicação de rótulos, pode-se considerar uma lista de termos previamente eleitos, de forma que uma ferramenta automática possa identificar a 
ocorrência deles em cada uma das frases do texto. Essa abordagem imediatamente nos remete à ideia de vocabulário controlado (VC).

O VC, conforme Siqueira (2011), é um importante instrumento para racionalização da recuperação de informação, pois organiza os pontos de acesso, minimizando os principais problemas do sistema: a duplicação e a dispersão informacional. Para a autora, o VC contribui para reduzir heterogeneidades terminológicas e para a legitimação das relações orgânicofuncionais, provocadas pelo exponencial aumento da massa informacional disponível na atualidade, o que torna exigível um olhar mais atento às necessidades dos usuários.

Lopes (2002) conceitua VC como um conjunto limitado de termos autorizados para uso na indexação e busca de documentos. Por termos autorizados se entendem os preferíveis de uso na indexação e busca, em detrimento de outros termos sinônimos ou correlatos. A finalidade do VC é fazer coincidir a linguagem do indexador com a do sujeito que busca informação, bem como a linguagem entre indexadores, padronizando o uso dos termos que utilizam para indexar os documentos.

Os instrumentos de controle vocabular podem aparecer como listas, taxonomias, tesauros e ontologias, por exemplo (TERRA, 2005). Uma ampla discussão sobre tipos de VC é apresentada por Harpring (2010), no qual se pode ler, em livre tradução nossa: "listas controladas são usualmente elaboradas para um banco de dados ou situação bem específicos e podem não ter utilidade fora do contexto" (HARPRING, 2010, p. 20). O presente trabalho baseia-se também nesse conceito.

\section{A PESQUISA: MÉTODOS E ANÁLISE DE DADOS}

Durante a revisão da literatura sobre os principais temas abordados neste artigo, realizou-se um levantamento bibliográfico a fim de se conhecer o universo de documentos produzidos pela CI, considerando-se o recorte cronológico de 2013 a 2016. Nesse sentido, concentrou-se o levantamento em bases de dados científicas da área de CI (ou em bases multidisciplinares, nas quais os pesquisadores da CI têm trabalhos publicados) utilizando-se, na estratégica de busca, como palavra-chave, o termo: "acessibilidade informacional".

Os metadados relativos aos trabalhos encontrados foram organizados, agrupados e incluem a descrição e localização dos itens, seus resumos e palavras-chave, de modo a favorecer a visualização dos seus objetivos e principais resultados. Com abordagem predominantemente descritiva e quantitativa, os dados foram analisados e classificados segundo suas semelhanças temáticas, utilizando-se a técnica de Análise de Conteúdo (BARDIN, 1977). Para tanto, foram

Comun. \& Inf., Goiânia, GO, v. 21, n. 1, p. 70-88, jan./mai. 2018. 
estabelecidas as seguintes categorias de classificação da literatura levantada e analisada: relatos de experiência, estudos de satisfação do usuário, avaliação de serviços e/ou produtos, desenvolvimento de tecnologias, entre outros, com base no objetivo geral de cada um dos itens do corpus documental.

Essa etapa de leitura e classificação dos documentos possibilitou uma visão panorâmica do que tem sido pesquisado em CI, bem como perceber, a partir dos resultados das pesquisas, o alcance e o impacto da CI sobre o tema da acessibilidade informacional.

Como resultado do levantamento bibliográfico, localizaram-se 87 documentos, dentre os quais $46(52 \%)$ são textos fortemente relacionados à CI, incluindo dissertações e teses defendidas em programas de pós-graduação.

Os demais 41 textos, $48 \%$ do total, foram encontrados publicados em periódicos multidisciplinares e, embora utilizem como uma de suas palavras-chave o termo "acessibilidade informacional", não se referem a pesquisas dentro do campo da CI. Verificou-se que partem de pesquisadores de outras áreas como Educação, Comunicação, Computação, Engenharia de Produção, Arquitetura e Urbanismo, Turismo, entre outras.

Isso habilita a clara conclusão de que a acessibilidade, mesmo a informacional, não é exclusividade da CI, sendo um tema de interesse multidisciplinar. Por "interesse multidisciplinar", nesse caso, não se deve compreender erroneamente que se trata de trabalhos em conjunto com a CI. São trabalhos desenvolvidos no tema, de forma totalmente isolada da CI.

Na Figura 1, pode-se observar a distribuição dos textos dentro do recorte cronológico da pesquisa, destacando-se, a cada ano, a produção total e a produção fortemente relacionada à CI.

Figura 1 - Levantamento bibliográfico sobre "acessibilidade informacional"

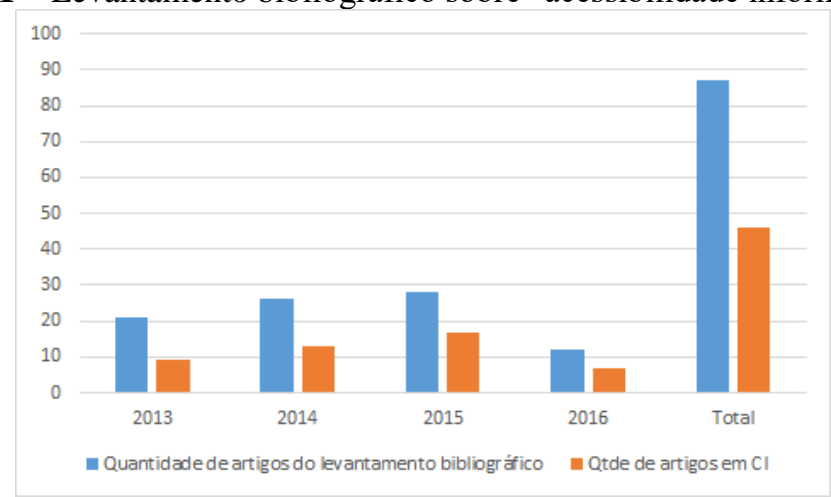

Fonte: Dados da pesquisa

Comun. \& Inf., Goiânia, GO, v. 21, n. 1, p. 70-88, jan./mai. 2018. 
Aprofundando-se a análise da literatura relativa aos 52\%, que são fortemente relacionados à CI, foram obtidos os dados que podem ser vistos na Figura 2.

Figura 2 - Temas dos trabalhos em CI relacionados à acessibilidade informacional

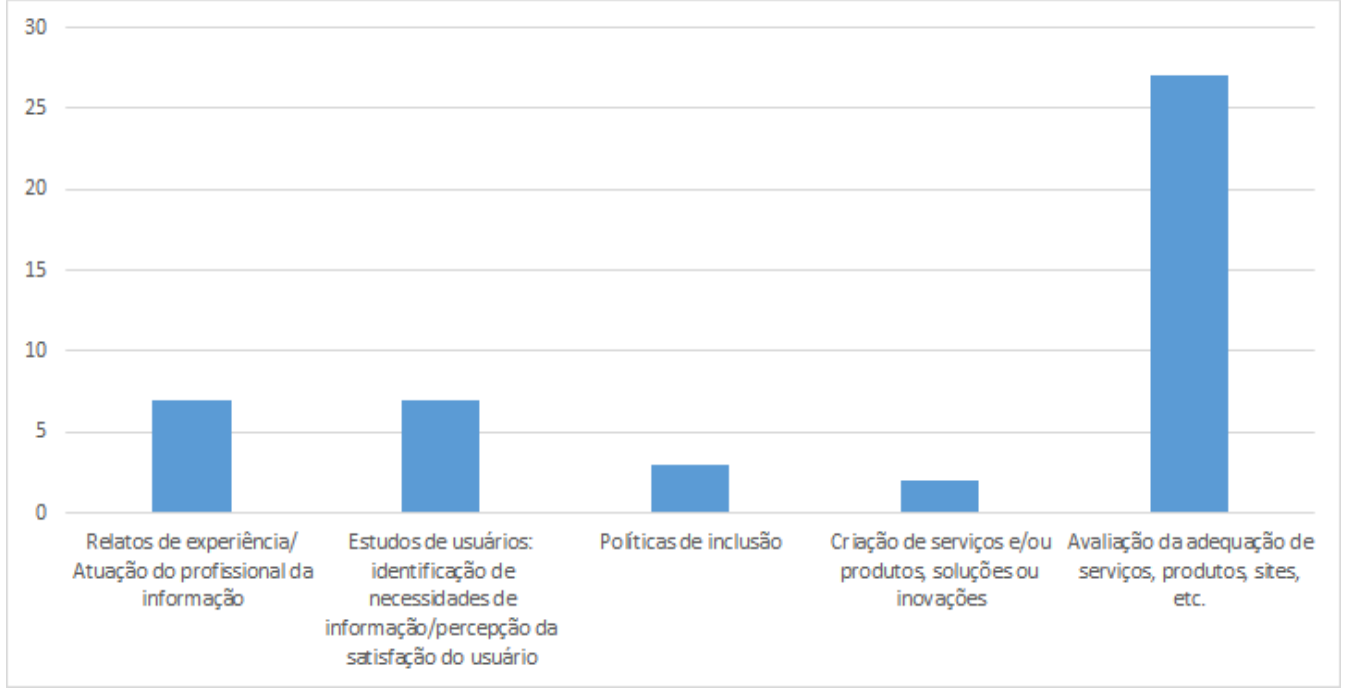

Fonte: Dados da pesquisa

Percebe-se, pela Figura 3, que dos trabalhos associados à CI, 27 (60\%) das publicações se referem à avaliação da acessibilidade de páginas Web, softwares, instalações ou produtos. Parte dessas publicações são respaldadas por fundamentos teóricos e parte são empíricas, baseadas exclusivamente na percepção/satisfação do usuário.

Essa proporção talvez se explique pelo fato de que quando o assunto ganhou visibilidade teria despertado o interesse de pesquisadores em conhecer se determinados produtos e serviços de informação, disponibilizados aos usuários, atendiam a critérios mínimos de usabilidade. Todavia, esse interesse maciço em avaliação de acessibilidade não produziu soluções técnico-práticas ou inovações, não propôs mudanças, não trouxe novos aportes teóricos e/ou aprimoramento de sistemas e/ou recursos, por exemplo, para acesso à informação na Web.

Conclui-se que a maioria desses esforços de pesquisa se caracteriza como quadros que retratam momentos específicos de certos recursos informacionais, sem que produzissem na CI a compreensão de que esse problema é, de fato, algo que ela deveria resolver. Compreende-se que não se minimiza o mérito e a necessidade do trabalho de diagnóstico realizado com essas

Comun. \& Inf., Goiânia, GO, v. 21, n. 1, p. 70-88, jan./mai. 2018. 


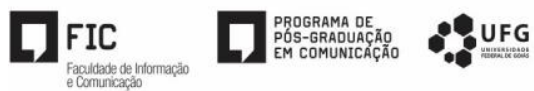

pesquisas, apenas sinaliza-se que soluções técnico-práticas ou inovações não aconteceram na mesma proporção.

Os assuntos das demais publicações dos pesquisadores da área de CI se dividem em: relatos de experiência/atuação do profissional da informação (7 textos); estudos de usuários/ identificação de necessidades de informação/percepção da satisfação do usuário (7 textos); políticas de inclusão (3 textos); criação de serviços (1 texto) e soluções ou inovações (1 texto).

Percebe-se que apenas 1 dos 46 documentos da CI se refere a algum tipo de proposta de solução ou inovação planejada a partir de diagnósticos de demanda/necessidades por parte dos usuários de informação com deficiência. Observa-se que houve muita avaliação, mas pouco se tem feito no sentido de aprimorar os itens avaliados ou criar soluções para amainar os pontos passíveis de melhoria, representando esforços de pesquisa que apenas apontaram problemas e poucas soluções.

O único texto que propôs uma ação afirmativa (dentro da CI) foi o de Souza e Tabosa (2014), que apresentam uma proposta de arquitetura de informação para a conversão de documentos hipertextos em documentos hipergeométricos, que preservam as características do original e adicionam uma funcionalidade assistiva e direcionada a deficientes visuais. Trata-se do único texto no qual o assunto acessibilidade informacional é abordado como um problema da CI, para além de um mero tema alegórico. A CI não pode ter uma postura meramente discursiva. É preciso propor e apresentar soluções.

Percebe-se que, embora o tema esteja presente na pauta de alguns pesquisadores, a CI praticamente não oferece soluções técnico-práticas ou inovações. No sentido de ratificar essa ausência da CI, no Quadro 1 apresentam-se todos os trabalhos (dentre os 87 que compuseram o corpus desta pesquisa) que relataram ou propuseram soluções técnico-práticas ou inovações e que, efetivamente, contribuíram para a obtenção de soluções para a melhoria da acessibilidade informacional com impactos positivos na mediação.

Pelos dados apresentados, percebe-se que a participação da CI em soluções técnicopráticas ou inovações dentro dessa área de pesquisa é ainda tímida, se considerarmos a relevância do tema e, em particular, se concordarmos com relação à pertinência do tema aos interesses de pesquisa da área.

Quadro 1 - Soluções técnico-práticas ou inovações no âmbito da acessibilidade informacional

Comun. \& Inf., Goiânia, GO, v. 21, n. 1, p. 70-88, jan./mai. 2018. 


\begin{tabular}{|c|c|c|}
\hline Autores & Objetivos do trabalho & Área de origem \\
\hline Santos (2013) & $\begin{array}{l}\text { Devido à escassez de páginas com recursos de } \\
\text { acessibilidade que atendam às necessidades de } \\
\text { pesquisa e estudo de alunos dos cursos de Química, } \\
\text { construiu uma página Web tornando seus conteúdos } \\
\text { acessíveis a pessoas com deficiência visual. A } \\
\text { construção da página teve como objetivo proporcionar } \\
\text { maior autonomia de estudo e pesquisa a alunos de } \\
\text { Química com deficiência visual, na perspectiva de } \\
\text { favorecer a inclusão escolar e digital. }\end{array}$ & Química \\
\hline $\begin{array}{l}\text { Souza e Tabosa } \\
\qquad(2014)\end{array}$ & $\begin{array}{l}\text { Apresentam uma proposta de arquitetura de } \\
\text { informação para a conversão de documentos } \\
\text { hipertextos em documentos hipergeométricos que } \\
\text { preservem as características do original e adicionem } \\
\text { uma funcionalidade assistiva otimizada direcionada a } \\
\text { deficientes visuais. }\end{array}$ & CI \\
\hline Carpes et al. (2014) & $\begin{array}{l}\text { Criaram uma mídia jornalística em formato de áudio, } \\
\text { garantindo a acessibilidade daqueles que não podem } \\
\text { ler, e, consequentemente, o direito à informação. }\end{array}$ & Comunicação \\
\hline $\begin{array}{l}\text { Santos, Ellwanger e } \\
\text { Losekann (2014) }\end{array}$ & $\begin{array}{l}\text { Apresentam uma solução computacional que tem } \\
\text { como objetivo orientar os utilizadores na } \\
\text { produção/adaptação de documentos digitais com vistas } \\
\text { a torná-los acessíveis. }\end{array}$ & Informática \\
\hline $\begin{array}{l}\text { Crespo, Espada e } \\
\text { Burgos (2016) }\end{array}$ & $\begin{array}{l}\text { Criaram uma plataforma que permite que um conjunto } \\
\text { de problemas de acessibilidade possa ser resolvido sem } \\
\text { modificar o código da página Web original. A } \\
\text { plataforma proposta é capaz de analisar sites e detectar } \\
\text { muitos problemas de acessibilidade automaticamente. } \\
\text { Depois disso, um assistente guiado é usado para } \\
\text { oferecer soluções adequadas para cada problema } \\
\text { detectado. }\end{array}$ & Computação \\
\hline
\end{tabular}

Fonte: Dados da pesquisa bibliográfica

\section{CONSIDERAÇÕES E CONCLUSÕES}

Com base no exposto, percebe-se que a CI tem muito mais a explorar sobre o tema da acessibilidade informacional, já que as publicações são relativamente parcas e os resultados das pesquisas na área poderiam ser bem mais profícuos se propusessem inovações tecnológicas que efetivamente impactassem no modo como os deficientes, por exemplo, apropriam-se da informação e a usam.

Comun. \& Inf., Goiânia, GO, v. 21, n. 1, p. 70-88, jan./mai. 2018. 
Para isso, provavelmente ela precisará se aliar (ou se aliar ainda mais) a outras áreas, como a Tecnologia da Informação, para poder oferecer soluções práticas para esses usuários, no que diz respeito à busca, processamento, recuperação e uso da informação.

Um possível caminho para que se avance, no sentido de maximizar a contribuição da CI, é se os programas de pós-graduação abraçassem esse tema em suas linhas de pesquisa, de maneira que mais pesquisadores, principalmente os de doutorado, passassem a se dedicar ao estudo e desenvolvimento de produtos e serviços originais, promovendo o desenvolvimento da área.

O uso de tecnologias assistivas, baseadas em PLN, VC ou qualquer outra técnica, no favorecimento da mediação da informação pode ser um caminho pelo qual a CI pode trazer significativas contribuições à sociedade. Ter acesso aos resumos dos textos, por exemplo, tornará mais produtiva a seleção dos materiais que realmente interessam ao usuário em geral.

Iniciativas como as apresentadas no Quadro 1 são importantes por promoverem o efetivo acesso à informação a uma parcela da população que estaria sendo negligenciada. É nesse sentido que compreendemos o uso das TA como instrumentos para a mediação da informação, tal como conceituada por Almeida Júnior (2009). Conforme o autor, essa mediação não pode ser considerada como coadjuvante no âmbito da CI, mas como algo de tamanha importância, que chega a interferir em seu próprio objeto, pois está, embora implícita, presente em todas as atividades do profissional da informação.

\section{REFERÊNCIAS}

ALMEIDA JÚNIOR, O. F. Mediação da informação e múltiplas linguagens. Pesq. bras. Ci. Inf., Brasília, v. 2, n. 1, p. 89-103, jan./dez. 2009.

ALMEIDA JÚNIOR, O. F.; BORTOLIN, S. Mediação da informação e da leitura. In: SEMINÁRIO EM CIÊNCIA DA INFORMAÇÃO, 2., 2007, Londrina. Anais eletrônicos... Londrina: UEL, 2007. Disponível em: 〈http://eprints.rclis.org/13269/>. Acesso em: 23 jul. 2016.

ASSOCIAÇÃO BRASILEIRA DE NORMAS TÉCNICAS. ISO 9241-11: requisitos ergonômicos para o trabalho com dispositivos de interação visual: parte 11: orientações sobre usabilidade. São Paulo: ABNT, 2011. Idêntica à norma publicada em 1998.

BARDIN, L. Análise de conteúdo. Lisboa: Edições 70, 1977.

BASTIEN, J. M. C., SCAPIN, D. Ergonomic Criteria for the Evaluation of HumanComputer interfaces. Paris: Institut National de Recherche en Informatique et en Automatique, 1993.

Comun. \& Inf., Goiânia, GO, v. 21, n. 1, p. 70-88, jan./mai. 2018. 
BERSCH, R. Introdução à tecnologia assistiva. Porto Alegre: CEDI, 2008. Disponível em: <http://migre.me/uaTPQ>. Acesso em: 20 jun. 2016.

BERSCH, R.; TONOLLI, J. C. Introdução ao conceito de tecnologia assistiva e modelos de abordagem da deficiência. 2006. Disponível em:

<http://www.bengalalegal.com/tecnologia-assistiva $>$. Acesso em: 18 jul. 2016.

BORKO, H. Information Science: what is it? American Documentation, v. 19, n. 1, jan., 1968.

CAPURRO, R.; HJORLAND, B. The concept of information. In: Annual Review of Information Science and Technology, v. 37, p. 343-411, 2003.

CARAN, G. M.; SANTINI, R. M.; BIOLCHINI, J. C. A. Use of social network to support visually impaired people: A Facebook case study. Transinformação, Campinas, v. 28, n. 2, p. 173-180, maio/ago. 2016.

CARPES, D. S. et al. Jornal Falado: ferramenta de acessibilidade de comunicação para os cegos. In: SOCIEDADE BRASILEIRA DE ESTUDOS INTERDISCIPLINARES DA COMUNICAÇÃO, 15., 2014, Florianópolis. Anais eletrônicos... Florianópolis: Unisul, 2014. Disponível em: <https://portalintercom.org.br/anais/sul2014/expocom/EX40-11671.pdf >. Acesso em: 18 jul. 2016.

COOK, A. M.; HUSSEY, S. M. Assistive technologies: principles and practices. St. LouisMissouri: Mosby - Year Book, 1995.

CRESPO R. G.; ESPADA J. P.; BURGOS D. Social4all: definition of specific adaptations in Web applications to improve accessibility. Computer Standards \& Interface, v. 48, p. 1-9, 2016.

GONZALEZ, M.; LIMA, V. L. S. Recuperação de informação e processamento da linguagem natural. 2003. Disponível em:

<http://www.inf.pucrs.br/ gonzalez/docs/minicurso-jaia2003.pdf> . Acesso em: 9 abr. 2016.

HARPRING, P. Introduction to Controlled Vocabularies: Terminologies for Art, Architecture, and Other Cultural Works. [S.1.]: Getty Reseach Institute, 2010.

JACOB, Elin K. Ontologies and the Semantic Web. Bulletin of the American Society for Information Science and Technology, April/May, 2003.

LOPES, I. L. Uso das linguagens controlada e natural em bases de dados: revisão da literatura. Ci. Inf., Brasília, v. 31, n. 1, p. 41-52, jan./abr. 2002.

MARTINS NETO, J. C.; ROLLEMBERG, R. S. Tecnologias assistivas e a promoção da inclusão social. 2005. Disponível em:

$\langle$ http://www.ciape.org.br/artigos/artigo_tecnologia_assistiva_joao_carlos.pdf $>$. Acesso em: 20 jun. 2016.

Comun. \& Inf., Goiânia, GO, v. 21, n. 1, p. 70-88, jan./mai. 2018. 
MELO, A. M.; COSTA, J. B.; SOARES, S. C. M. Tecnologias assistivas. In: PUPO, D. T.; MELO, A. M.; FERRÉS, S. P. (Org.). Acessibilidade: discurso e prática no cotidiano das bibliotecas. Campinas: Unicamp, 2006. p. 62-70.

MORAES, M.; CARELLI, A. E. A interdisciplinaridade na Ciência da Informação pela perspectiva da análise de citações. Em Questão, v. 22, n. 1, p. 137-160, 2016.

NICHOLL, A. R. J.; BOUERI FILHO, J. J. O ambiente que promove a inclusão: conceitos de acessibilidade e usabilidade. Revista da Faculdade de Engenharia e Arquitetura e Tecnologia, Marília v. 3, n. 2, p. 46-61, dez. 2001. Disponível em: $<$ http://www.unimar.br/publicacoes/assentamentos/assent_humano3v2/Antony\%20e\%20jose. htm >. Acesso em: 02 fev. 2017.

PAULA, S. N. Acessibilidade à informação em bibliotecas universitárias e a formação do bibliotecário. Campinas: Universitária PUC, 2009.

PEREIRA, S. L. Processamento de Linguagem Natural. 2011. Disponível em: <http://walderson.com/2011-2/IA/07-processamentolinguagemnatural.pdf $>$. Acesso em: 09 mar. 2016.

PONTES, E. L.; LINHARES, A. C.; TORRES-MORENO, J.-M. SASI: sumarizador automático de documentos baseado no problema do subconjunto independente de vértices. In: SIMPÓSIO BRASILEIRO DE PESQUISA OPERACIONAL, 46., 2014, Salvador. Anais eletrônicos... Salvador: [s.n.], 2014. Disponível em: <http://www.din.uem.br/sbpo/sbpo2014/pdf/arq0353.pdf > . Acesso em: 08 mar. 2016.

RADABAUGH, M. P. The Engineering Handbook of Smart Technology for Aging, Disability and Independence. [S.1.]: John Wiley \& Sons. 2008.

SANTOS, C. G.; ARAÚJO, W. J. Acessibilidade informacional: um estudo sobre configurações de segurança em objetos digitais acessíveis segundo análise de aceitação por pessoas com deficiência visual. Pesquisa Brasileira em Ciência da Informação e Biblioteconomia, v. 10, p. 209-222, 2015.

SANTOS, C. P.; ELLWANGER, C.; LOSEKANN, M. Avaliação de acessibilidade para documentos digitais: uma aplicação no contexto educacional. In: CONGRESSO BRASILEIRO DE INFORMÁTICA NA EDUCAÇÃO, 3., 2014, Dourados. Anais eletrônicos... Dourados: SBC, 2014. Disponível em: <http://www.brie.org/pub/index.php/sbie/article/view/2950>. Acesso em: 18 jul. 2016.

SANTOS, G. A. M. Página Web com conteúdos de química acessível a estudantes com deficiência visual. 2012. 103 f. Dissertação (Mestrado em Ensino de Ciências)-Universidade de Brasília, Brasília, 2013.

SARACEVIC, T. Ciência da Informação: origem, evolução e relações. Perspec. Ci. Inf., Belo Horizonte, v. 1, n. 1, p. 41-62, jan./jun. 1996. 
SIQUEIRA, J. C. Recursos linguísticos para análise de vocabulário controlado: o caso do SAUSP. Biblionline, João Pessoa, v. 7, n. 2, p. 52-62, 2011.

SOUZA, M. S. et al. Acessibilidade e inclusão informacional. Informação \& Informação, v. 18, n. 1, p. 1-16, jun. 2013. Disponível em:

<http://www.uel.br/revistas/uel/index.php/informacao/article/view/12173 > . Acesso em: 13 jun. 2016.

SOUZA, O de. A usabilidade na perspectiva do uso da informação: estatísticas das pesquisas sobre o tema no Brasil. Informação \& Sociedade, v. 25, n. 1, p. 159-172, 2015. Disponível em: <http://www.ies.ufpb.br/ojs2/index.php/ies/article/view/159/13196>. Acesso em: 18 jul. 2016.

SOUZA, O. de; TABOSA, H. R. A eficácia dos modelos de recuperação de informações: um estudo particularizado na comunicação científica na Web. In: ENCONTRO NACIONAL DE PESQUISA EM CIÊNCIA DA INFORMAÇÃO, 16, 2015, João Pessoa. Anais eletrônicos... João Pessoa: ANCIB, 2015. Disponível em: 〈http://migre.me/uaTPc〉. Acesso em: 22 jun. 2016.

Virando a página: um novo conceito de acessibilidade na web para deficientes visuais. Informação \& Sociedade, v. 24, n. 1, 2014. Disponível em: <http://search.proquest.com/openview/dfe2d00524397bf559f55b5e1ee3d27d/1?pqorigsite=gscholar $>$. Acesso em: 18 jul. 2016.

TERRA, J. C. C. et al. Taxonomia: elemento fundamental para a gestão do conhecimento. 2005. Disponível em: 〈http://migre.me/tQM81>. Acesso em: 17 maio 2016.

VIEIRA PINTO, A. O conceito de tecnologia. 2. ed. Rio de Janeiro: Contraponto, 2005. 